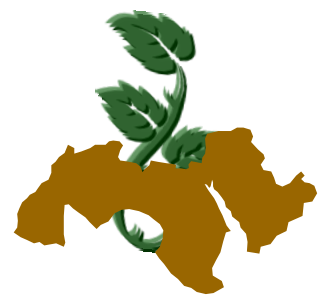

Arab Univ.

J. Agric. Sci., Ain Shams Univ., Cairo, 18(1), 77-86, 2010

\title{
STABILITY OF SOME FLAVOR EMULSIONS AGAINST GRAVITATIONAL SEPARATION AFTER REDUCING THE AMOUNT OF GUM ARABIC IN THE FORMULATION
}

Edris', A.E.

1- Aroma and Flavor Chemistry Department, National Research Center, Cairo, Egypt

Keywords: Flavor emulsions; Gum Arabic; Stability; Weighting agents; Density

\section{ABSTRACT}

Gum Arabic (GA), a natural plant extract, is frequently used for the preparation and stabilization of flavor emulsions that is commonly used in soft drink and flavored beverage industry. This study aimed to reduce the amount of GA in some flavor model emulsions for cost effectiveness and studying the effect of that on the stability of these emulsions against gravitational separation during storage. Five flavor model emulsions were formulated using pure citral and cinnamic aldehyde and their mixtures at different weight ratios. Results indicated that a flavor/gum ratio $1: 1$ or $1: 0.5$ was not able to stabilize the particle size of all emulsions which is manifested by increase in size by many folds during storage. Similarly, four of the flavor model emulsions showed instability behavior (creaming or sedimentation) toward gravitational separation at the same flavor/gum ratios.

However, only one flavor model emulsion out of the five models showed a high stability against gravitational separation at flavor/gum ratio $1: 1$ or even 1:0.5. That emulsion model was characterized by having a density matching (similarity) between its dispersed flavor phase and its continuous water phase. This indicates the possibility of formulating some flavor emulsions with reduced amounts of gum Arabic only by matching the density between the flavor phase and the continuous phase of the emulsion.

\section{INTRODUCTION}

Gum Arabic (GA) is the dried gummy exudation obtained from various species of Acacia trees like
Acacia senegal and Acacia seyal which belong to the Leguminosae family (Martin, 1969). GA is extensively used to stabilize the concentrated flavor oil emulsions which is used to impart flavor to beverages and soft drink industries (Given, 2009, Mirhosseini et al 2008a,b and D'Angelo, 2006). Randall et al (1988) indicated that the emulsifying properties of GA originate from the proteinacious fraction content of the gum namely arabiogalatan protein and glycoprotein. The proteinacious fraction represents only $10 \%$ of the total gum molecule though; it contains most of the gum protein (Thevenet, 1988). That fraction has surface active properties thus it decreases the interfacial tension between the flavor oil and water which stabilizes the emulsions. The proteinacious fraction is also responsible for imparting charge repulsion between oil droplets in the emulsion which prevents them from flocculation and coalescence leading to more emulsion stability (Jayme et al 1999). Beside the proteinacious fraction, GA also contains arabinogalactan fraction which represents $90 \%$ of the gum molecule and composed of complex polysaccharides (Thevenet, 1995). This fraction is characterized by low viscosity and high solubility in water and most of all it has an excellent film forming properties around the oil droplets. This prevents droplets from coalescing, thus it contributes further to the emulsions stability. Another advantage of using GA to stabilize flavor emulsions is that it is more stable toward droplet flocculation in the presence of electrolytes (Mc Clements, 2004), which is not the case with protein-stabilized flavor emulsions. However GA is considered to be a poor emulsifier compared with other pure proteins derived from milk (e.g whey protein, casine, sodium caseinate). Thus the amount of GA should be increased to about ten times to get the same emulsion stability as that of the corresponding protein- 
stabilized emulsion (Dickinson and Galazka, 1991). For this reason the oil:GA ratio of $1: 2.0$ (Williams and Phillips, 2000) or 1:2.5 (Thevenet, 1995) or even 1:3 (McClements, 2005) is usually used to stabilize flavor oil emulsions.

Due to the fluctuation of the GA supply and prices, a strong trend is growing in the industry to replace it with another steady supply and affordable emulsifiers (Seisun, 2002). Starch derivatives were found to be a potential candidate for substituting GA (Taherian et al 2006 and Tesch et al 2002). This group of synthetic surface active starches showed good emulsifiying properties but the natural identity provided with GA can not be fulfilled with these synthetic starches. Recently, other natural substitutes of GA were investigated like corn fiber gum (Yadav et al 2009, 2007) and covalently bonded milk protein-maltodextrin conjugates (Akhtar and Dickinson, 2007).

Beside gum substitution, a trend is developed to reduce the amount of GA in the beverage emulsions. This can also help in slowing down the depletion of the affordable market supply but that will be on the expense of emulsion stability. It was found that the minimum amount of GA that can stabilize O/W emulsion is $1: 1 \mathrm{wt} \%$ (based on soy bean oil, McNamee et al 1998). Further reduction of the amount of GA leads to dramatic increase in the particle size and emulsion separation.

On the same trend of reducing the amount of GA in flavor emulsions, the author aimed in this investigation at studying the stability behavior of some flavoring model emulsions against gravitational separation, using low amounts of GA. The flavor model is composed of citral, cinnamic aldehyde and their blends at different weight ratios. The flavor to gum weight ratio used was $1: 1$ and $1: 0.5$. All the formulations were prepared using GA as a sole emulsifier.

\section{MATERIALS AND METHODS}

\section{Chemicals}

Gum Arabic from Acacia tree (reagent grade. CAS No. 9000-015), trans-Cinnamic aldehyde (99.0+\%, CAS No.14371-10-9) and citral (95.0\% CAS No. 5392-40-5) were purchased from SigmaAldrich Inc. (St. Louis, MO, USA).

\section{1- Preparation of the flavoring model blends}

The flavoring models (as an oil phase in the emulsion) comprised five different blends which were composed of pure citral and cinnamic aldehyde either alone or in combination with each other at different weight ratios as given in Table (1). The five flavoring blends were denoted in this investigation by $\mathrm{B} 1, \mathrm{~B} 2, \mathrm{~B} 3, \mathrm{~B} 4$ and $\mathrm{B} 5$.

\section{2- Preparation of the flavoring emulsions}

Two main groups of emulsions of different flavoring material : GA ratios were prepared. The first group: was formulated using a weight ratio of flavor: $G A=1: 1$. The second group of emulsions was formulated using weight ratio of flavor: $\mathrm{GA}=$ 1: 0.5 .

The two groups of emulsions were formulated using the same amount of the flavoring model blends as oil phases. Details of the emulsion groups and the emulsion formulae were tabulated in Table (1).

The emulsion was prepared by allowing GA to hydrate in distilled water with gentle stirring using magnetic bar followed by the addition of the flavoring blend. The emulsions were pre-homogenized for 2 minutes at 20,000 rpm using high speed homogenizer (tissue terror model 985370-395, Biospec products, Inc). Then they were microfluidized for 5 cycles using microfluidizer ( M-110Y microfluidic, Newton, MA). The inlet air pressure was 75 psi ( $510 \mathrm{kPa})$ at the regulator gauge which was magnified $(x 232)$ inside the interaction chamber to reach 17400 psi ( 119.9 $\mathrm{MPa})$. The emulsions were cooled during the microfluidization cycles using an ice bath. Finally, the emulsions were stored in dark glass bottles. Certain volumes of each emulsion were carefully transferred into flatbottom cylindrical glass tubes (100 mm height) designed especially to fit into optical scanning instrument (Turbiscan) to investigate emulsion stability through backscattering measurements as will be discussed later. All preparations were stored for 1 week at $4^{\circ} \mathrm{C}$.

\section{3- Measurement of emulsion stability}

Emulsion stability against gravitational separation (creaming or sedimentation), was measured by using the instrument for the optical characterization of a liquid dispersion (Turbiscan classic MA 2000, formulaction, Toluse, France). The fresh emulsions were contained in a cylindrical glass measurement cell with flat-bottom which is completely scanned from bottom to top with a light source (near infrared $\lambda=850 \mathrm{~nm}$ ). Two synchronous detectors collect transmission and backscattering 
data and reading head scans the entire length of the sample (about $55 \mathrm{~mm}$ ) acquiring transmission and backscattering every $40 \mu \mathrm{m}$. A transmission detector receives the light that goes through the sample while the backscattering detector receives the light backscattered by the sample. A pattern of the light flux as a function of the sample height is obtained. The results are reported as creaming/ sedimentation backscattering value profile versus emulsion height. An increased backscattered light at the bottom of the cell means sedimentation while a decrease backscattered light at the bottom means creaming

Scans were performed for all emulsions at the zero time, just after preparation, and then after 1 week of storage at $4^{\circ} \mathrm{C}$. Each scans provided a curve and all curves are overlaid on one graph to show stability at the end of storage period.

\section{4- Measurement of particle size}

Particle size was measured by using dynamic light scattering Nano-ZS (Nanoseries, Malvern Instruments, UK). Measurements were done at $25^{\circ} \mathrm{C}$, with a fixed angle of $172^{\circ}$. Sizes quoted are the z-average mean $(\mathrm{dz})$ for the droplet hydrodynamic diameter $(\mathrm{nm})$. Each sample was measured at least 3 times; data reported was mean \pm S.D

\section{5- Measurements of density}

The density of pure citral and pure cinnamic aldehyde and their blends at 25.0: 75.0 weight ratio (blend number B4, Table 1) were measured at $27^{\circ} \mathrm{C} \pm 2$ using a pyrex Becknometer equipped with a thermometer. First the clean instrument was weight empty then filled with excess distilled water until it came out from the side arm of the Becknometer to evacuate the instrument totally from air bubbles. The instrument was dried using soft tissue from the outside to remove the dripped water traces then re-weight and the difference in weight represents the actual volume capacity of the Bechnometer under the conditions of the experiment, considering the density of distilled water is 1 . After that, water was evacuated and the Bechnometer was washed with absolute alcohol, air dried, weighed empty again, then filled with the target pure citral or cinnamic aldehyde or their blend (B4) and re-weighed. From the weight of the sample and the volume of the Bechnometer, the density of the samples was determined. Each experiment was repeated twice.

\section{RESULTS AND DISCUSSION}

\section{1- Emulsion stability regarding the particle size}

Figure (1) showed the particle size distribution of emulsions containing five flavoring blends stabilized with two different amount of GA at the zero time of storage. Evidently, the emulsion containing $100 \%$ GA (flavor/gum ratio 1:1) shows smaller particle size compared with the particle size exhibited by the emulsion containing $50 \%$ GA (flavor/gum ratio 1: 0.5$)$. This is not surprising to the author since high GA content reduced the interfacial tension between the water phase and the flavoring oil phase which facilitate breaking down of the flavoring particles into smaller ones during microfluidization. It is worth mentioning that, a high standard deviation among the replicate measurement of particle sizes ranging from \pm 7 to \pm 40 was observed in all emulsions (data not shown). This may be ascribed to the insufficiency of GA to cover the particles with interfacial monolayer. Thus during microfluidization, some particles which are not fully covered with the gum can re-coalesce (join together) in the interaction chamber of the microfluidizer leading to some larger particles that cause that high standard deviation during particle size measurements. Storing the emulsions samples for one week resulted in dramatic increase in the particle size for all the flavoring emulsion (Fig. 2). The increase was pronounced especially for the low gum-containing emulsions $(50.0 \%)$ compared with the zero time measurements (Fig. 1). This indicates that GA even at $100.0 \%$ (flavoring/gum 1:1) is not sufficient to keep the small particle size of the emulsions at their initial values before storage (zero time). From these results it is clear that GA amount should be increased more than 100 wt.\% (on flavoring basis) in order to cover the surface of all flavoring droplets and hence stabilizes the particle size of the flavor emulsions during storage.

\section{2- Emulsion stability regarding gravitational separation}

Fig. (3a) represents the back scattering (BS) patterns of the emulsions containing five flavor model blends that formulated with flavor/gum ratio 1: 0.5 (50.0\% on flavor basis), at the zero time of storage. It is shown that the back scattering values were constant across the entire height of the emulsions tubes for all samples, which indicate an initial stability against gravitational separation. However, the BS \% value for emulsion containing $100 \%$ 
Table 1. Composition and formulation of the emulsions and the flavoring model blends

\begin{tabular}{|c|c|c|}
\hline & \multicolumn{2}{|c|}{ Emulsion groups } \\
\hline & $\begin{array}{l}\text { Group I: } \\
\text { flavor/gum ratio }(1: 1)\end{array}$ & $\begin{array}{l}\text { Group II: } \\
\text { flavor/gum ratio }(1: 0.5)\end{array}$ \\
\hline & $\begin{array}{l}\text { Formula: } \\
\text { water }(96 \mathrm{~g}) \\
\text { flavoring blend }(2 \mathrm{~g}) \\
\text { gum }(2 \mathrm{~g})\end{array}$ & $\begin{array}{l}\text { Formula } \\
\text { water }(97 \mathrm{~g}) \\
\text { flavoring blend }(2 \mathrm{~g}) \\
\text { gum }(1 \mathrm{~g})\end{array}$ \\
\hline Flavoring blend & \multicolumn{2}{|c|}{ Composition of the flavoring model blends (wt\%) } \\
\hline B1 & \multirow{5}{*}{\multicolumn{2}{|c|}{$\begin{array}{lll}\text { citral } 100.0: & \text { cinnamic aldehyde } 0.0 \\
\text { citral } 75.0 & \text { : cinnamic aldehyde } 25.0 \\
\text { citral } 50.0 & : \text { cinnamic aldehyde } 50.0 \\
\text { citral } 25.0 & \text { : cinnamic aldehyde } & 75.0^{*} \\
\text { citral } 0.0: & \text { cinnamic aldehyde } & 100.0\end{array}$}} \\
\hline B2 & & \\
\hline B3 & & \\
\hline B4 & & \\
\hline B5 & & \\
\hline
\end{tabular}

* This wt\% ratio is equivalent to molar ratio of $1: 3.531$ for citral and cinnamic aldehyde, respectively

Table 2. Density measurements of pure citral, cinnamic aldehyde and their blend (B4)

\begin{tabular}{|c|c|c|c|c|}
\hline \multicolumn{4}{|c|}{ Density at 27\% } \\
\hline \multicolumn{2}{|c|}{$\begin{array}{c}\text { Flavoring blend (B1) } \\
\text { (citral 100.0\%) }\end{array}$} & \multicolumn{2}{|c|}{$\begin{array}{c}\text { Flavoring blend (B5) } \\
\text { (cinnamic aldehyde 100.0\%) }\end{array}$} & $\begin{array}{c}\text { Flavoring blend (B4) } \\
(25.0 \% \text { citral: 75.0\% } \\
\text { cinnamic aldehyde) }\end{array}$ \\
\hline $\begin{array}{c}\text { indicated by } \\
\text { the } \\
\text { manufacturer }\end{array}$ & experimental & $\begin{array}{c}\text { indicated by } \\
\text { the } \\
\text { manufacturer }\end{array}$ & experimental & experimental \\
\hline 0.888 & 0.884 & 1.05 & $1.043 \pm 0.001$ & $0.998 \pm 0.001^{*}$ \\
\hline
\end{tabular}

* Very close to the density of distilled water which is 1.000

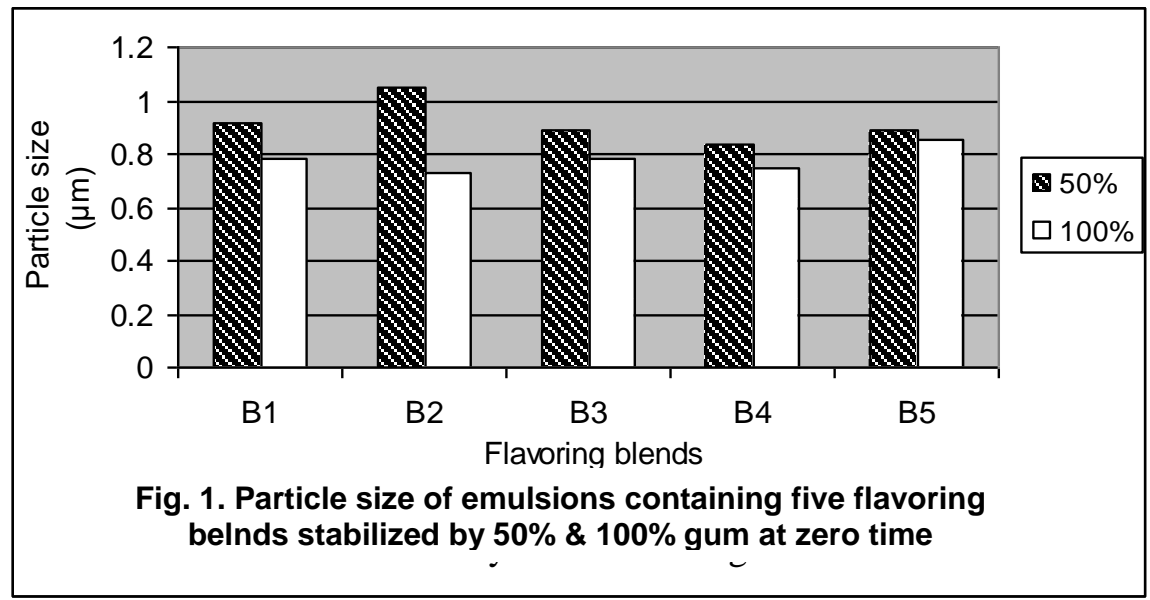

Arab Univ. J. Agric. Sci., 18(1), 2010 


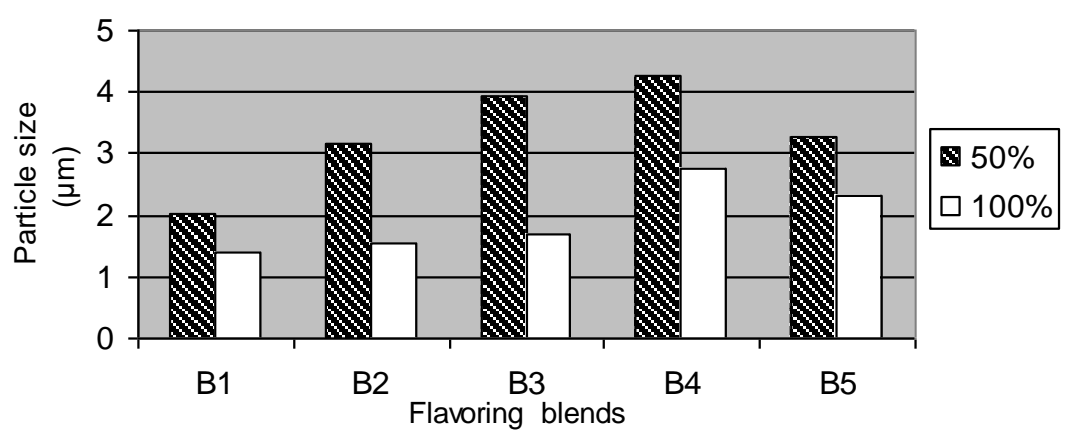

Fig. 2. Particle size of emulsions containing five flavoring belnds stabilized by $50 \%$ \& $100 \%$ gum after one week of storage
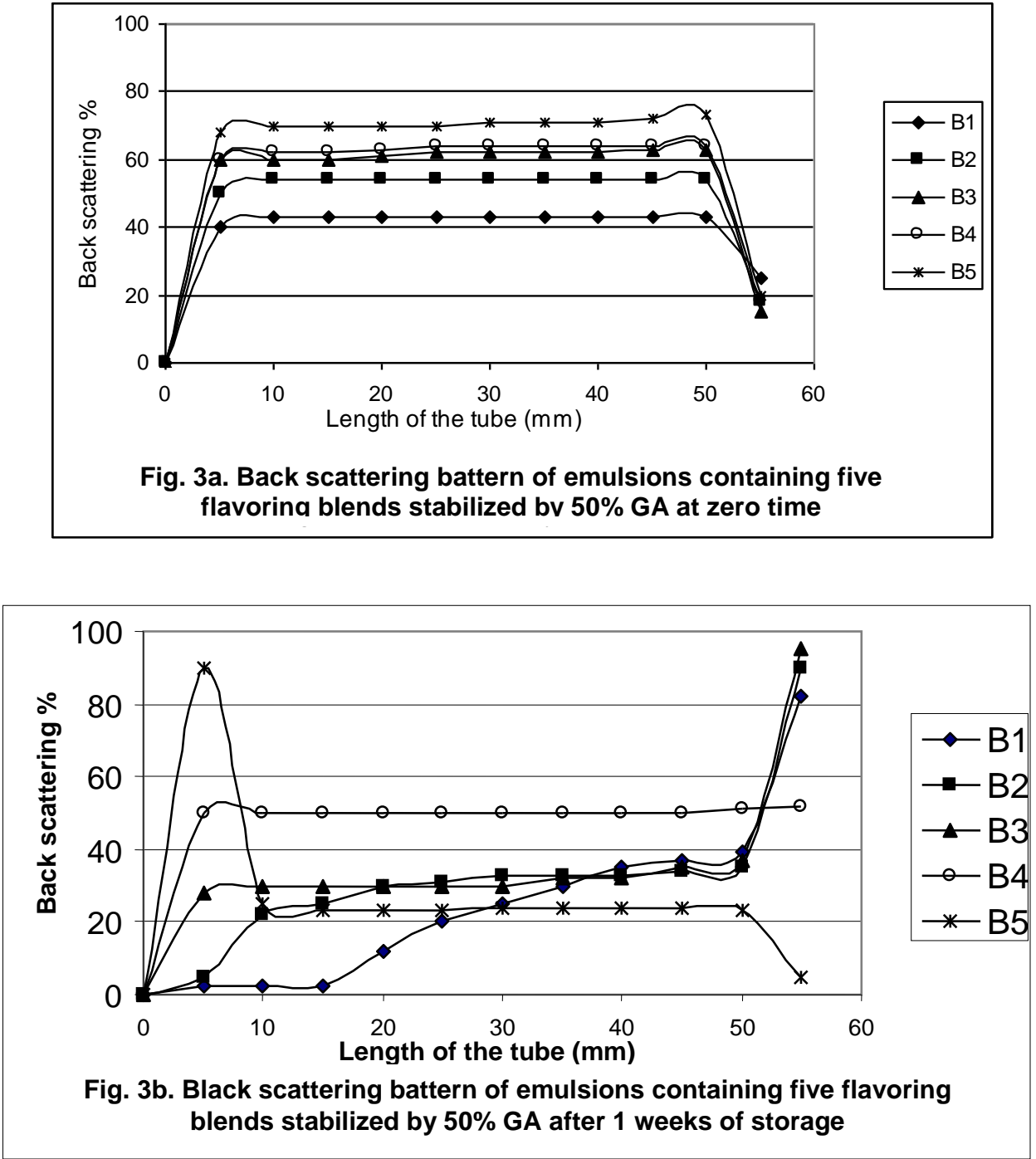

Arab Univ. J. Agric. Sci., 18(1), 2010 
citral (B1) is less than those of the emulsion containing $100 \%$ cinnamic aldehyde (B5). The same trend was found in Fig. 4(a) in which the weight ratio of oil/gum is 1: 1 (100.0\% on oil basis). This may be attributed to the difference in their refractive indices, i.e. for citral $=1.4876$ whereas for cinnamic aldehyde $=1.6209$. As the weight fraction of cinnamic aldehyde was increased in the flavoring blends from B1 to B5, the back scattering values also were increased until it reached its maximum at blend B5 (100\% cinnamic aldehyde). Fig. (3b) showed the stability of the different flavoring emulsions against gravitational separation after storage period of one week. Fig. (3b) depicts also that the emulsion containing the flavor model blend B5 (100.0\% cinnamic aldehyde) gave the highest BS value $(\sim 90.0 \%)$ at $5 \mathrm{~mm}$ from the bottom of the emulsion tube (left upper side on the graph), indicating high particle density at the bottom. Meanwhile, the same blend (B5) gave the lowest value of $\mathrm{BS}$ at $55 \mathrm{~mm}$ above the bottom of the emulsion tube ( $5 \%$, right lower side on the graph), indicating low particle density at the top of the emulsion tube. This is a typical gravitational instability symptom indicating sedimentation of the emulsion due to the high density of its flavoring blend compared with water (B5: cinnamic aldehyde, $d=1.043$, (Table 2 and Fig. 5).

On the contrary, emulsions containing the flavoring blends B1, B2, B3 showed an opposite behavior where the higher particle density was found at the top of the emulsion tube (82\%-98\%, right upper part on the graph), while the lower particle density was found at the bottom (left lower part on the graph). This pattern is typical gravitational instability symptom indicating creaming of these emulsions due to the low density of their flavoring blends (Fig. 5). The same behavior was exhibited for B1, B2, B3 and B-5 (Fig. 4b) where the weight ratio of flavoring to gum was 1: 1 (100.0\% on flavor basis).

Figs. (3b \& $\mathbf{4 b}$ ) depicts that the emulsion containing the flavor model blend B4 (citral 25.0\%: cinnamic aldehyde $75.0 \%$. Table (1) showed completely different back scattering behavior compared with those of the other four flavoring blends. The back scattering value was almost fairly constant across the entire height of the emulsion tube compared with the emulsions containing blends B1-B3 and B5. This indicates stability against gravitational separation regardless of the flavor: gum ratio (1:0.5 or $1: 1)$ and regardless of the particle size which was unstable for this flavor blend as shown during the storage period (Fig. 2). The plausible justification of that stability against gravitational separation is based on the probability of density matching (similarity) between the dispersed flavoring components of blend B4 with water which is the continuous phase of the emulsion. This matching can prevent the flavor droplets from creaming or sedimentation leading to stability against gravitational separation. This assumption may be confirmed from the results of density measurement which is shown in Table (2). The density of the flavoring blend is $0.998 \mathrm{~g} / \mathrm{cm}^{3}$, i.e. almost of the same order of distilled water density $\left(1.0 \mathrm{~g} / \mathrm{cm}^{3}\right)$.

The question now is how the density of blend B4 has reached that value $(0.998)$ although the density of its individual components citral and cinnamic aldehyde is $0.884 \mathrm{~g} / \mathrm{cm}^{3}$ and $1.043 \mathrm{~g} / \mathrm{cm}^{3}$ respectively in their pure states (Table 2 )? One may assume that blending citral and cinnamic aldehyde in B4 at weight ratios $25.0 \%$ : $75.0 \%$ (equivalent to molar ratio $1: 3.531$ respectively) was able to change the density of each component in a way that the blend density became 0.998 $\mathrm{g} / \mathrm{cm}^{3}$. In another words, one component in a certain weight fraction or molar ratio can act as an inherent density adjusting agent (also called: weighting agent) for the other component when both of them blended together. This inherent density adjustment was not fulfilled at the other flavoring blends B1, B2, B3 and B5 may be due to the difference in their weight ratios compared with B4. This justified their instability towards gravitational separation either due to creaming, B1-B3 or sedimentation B5. It worth mentioning that blending citral and cinnamic aldehyde at 0.25: 0.75 wt ratios (B4) may be associated with a change in the molar volume of each component with the resultant blend density being $0.998 \mathrm{~g} / \mathrm{cm}^{3}$.

Stokes' law governs the relation between the velocity of emulsion separation due to gravity and the density difference between the dispersed oil phase and the continuous water phase as follows:

$$
V=\frac{2 g r^{2}\left(d_{1}-d_{2}\right)}{9 \dot{\eta}_{2}}
$$

V: velocity or oil droplet movement (creaming or sedimentation)

$\mathrm{g}$ : acceleration due to gravity

$d_{1}, d_{2}$ : density of oil and water phases, respectively r: radius of oil droplet

ń2: viscosity of water phase 

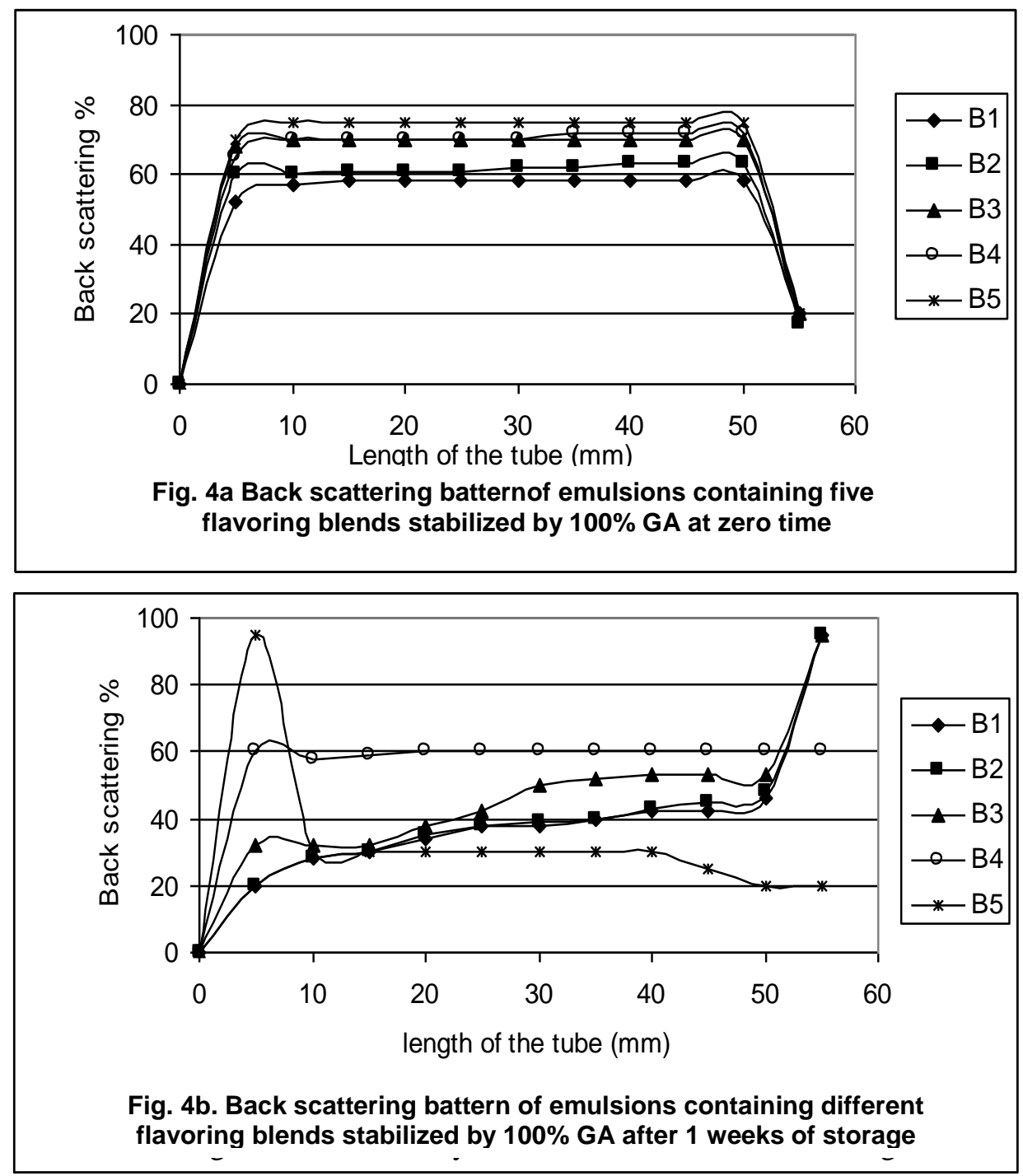

Thus to slow the process of gravitational separation of an emulsion, the numerator in the equation has to be reduced either by reducing the particle size $(r)$ and/or reducing the density difference between the oil phase and water $\left(d_{1}-d_{2}\right)$ which is the role of weighting agents. Justification of the stability of emulsion containing flavoring blend (B4) against separation may be ascribed to the fulfillment of the above-mentioned conditions.

In soft drink industry, synthetic density adjusting agents (weighting agents) are used to stabilize the flavoring beverage emulsions against gravitational separation (Taherian et al 2008 and Chanamai and McClements, 2000). Even when gum Arabic is used at oil/gum ratio $1: 2$, density adjusting agents are still needed at $50 \mathrm{wt} \%$ (based on oil) to give a stable emulsion (Williams and Phillips, 2000). Examples of these synthetic density adjusting agents are brominated vegetable oil (BVO,d= 1.33), estergum $(d=1.1)$, sucrose acetate isobutyrate (SAIB, $d=1.15$ ) (Chanamai and McClements 2000). However, some of these agents (e.g. SAIB) are not permitted in certain countries like USA, and others are limited to only $15 \mathrm{ppm}$ in the final product (e.g. BVO). Thus there are some limitations and restrictions of using these density adjusting agents in beverage emulsions. 


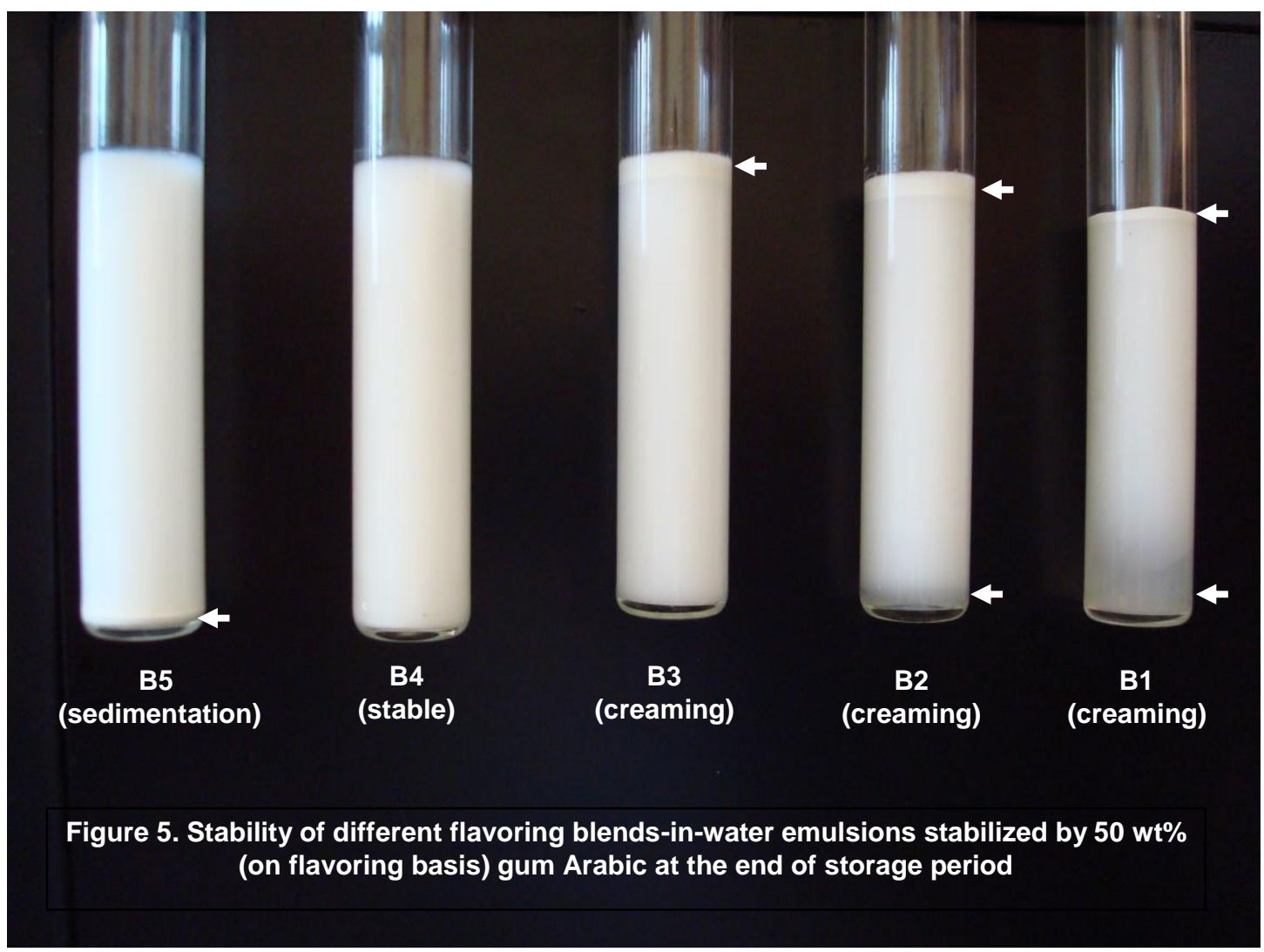

\section{CONCLUSION}

Reducing the amount of gum Arabic in flavoring model emulsion to $100 \%$ or $50 \%$ (based on flavor weight) failed to keep the particle size of the dispersed flavor droplets small and stable. These particles grow within one week of storage at $4^{\circ} \mathrm{C}$. However, the study also showed that the density of certain flavoring blend can be self-adjusted to match the density of the continuous phase of the emulsion (water), leading to stability against gravitational separation. This can be attained by carful selection of the type of flavoring components, their density and their weight ratios in the blend. If these conditions are taken into consideration, the emulsion can be stable against gravitational separation even at the lowest amount of gum $(50.0 \%$ on flavor weight). These results have a promising application in formulating flavor emulsions for the soft drink and beverage industry with low gum Arabic content and without need to use synthetic density adjusting agents. This proposal represent a challenge for the flavor technologist to formulate a selfdensity adjusted flavoring blend that match the density of the continuous phase in emulsion and at the same time is capable of delivering the desired aroma and flavor impact. That investigation can be further extended in the future to check the stability of these flavor emulsions during longer periods of storage time.

\section{ACKNOWLEDGMENTS}

The author is indebted to Prof. J. Weiss, formerly at the Food Biophysics lab, Food Science Department, University of Massachusetts, USA, for hosting the author Amr Edris and for putting all the necessary materials and equipments under the disposal of the author during this study. The author also thanks the Fulbright foundation and the $\mathrm{Na}$ tional Research Center, Egypt for financial support.

\section{REFERENCES}

Akhtar, M. and E. Dickinson (2007). Whey protein-maltodextrin conjugates as emulsifying agents: An alternative to gum Arabic. Food Hydrocolloids 21: 607-616. 
Chanamai, R. and J. McClements (2000). Impact of weighting agents and sucrose on gravitational separation of beverage emulsions. J. Agric. Food Chem. 48: 5561-5565.

D'Angelo, L. (2006). Application of the hydrocolloids in the beverage industry. In: Gums and Stabilizers for the Food Industry 13, p. 427. eds. Williams P. \& G. Phillips, RSC publishing. The proceedings of the $13^{\text {th }}$ Gums and Stabilizers for the Food Industry Conference held on 20-24 June 2005 at NEWI, Wrexham, UK.

Dickinson, E. and V. Galazka (1991). Emulsifying behavior of gum Arabic. Part 1: Effect of the nature of the oil phase on the emulsion droplet-size distribution. Carbohydrate Polymers. 14: 373-383.

Given, P. (2009). Encapsulation of flavors in emulsions for beverages. Current Opinion in Colloid \& Interface Sci., 14: 43-47.

Jayme, M.; D. Dunstan; and M. Gee (1999). Zeta potentials of gum arabic stabilized oil in water emulsions. Food Hydrocolloids. 13(6): 459-465.

Martin, G. (1969). In: Gum Technology in the Food Industry, p. 82. Academic Press, New York. McClements, D.J. (2005). In: Food Emulsions: Principles, Practices and Techniques, p. 528. Second Edition. CRC Serious in Contemporary Food Science. CRC Press, New York.

Mc Clements, J.D. (2004). Role of hydrocolloids as emulsifiers in foods. In: Gums and Stabilizers for the Food Industry 12, pp. 381-393 eds. Williams, P. and G. Phillips; Royal Society of Chemistry. Cambridge, UK. Special Publication No. 294.

McNamee, B.; E. O'Riordan and M. O'Sullivan (1998). Emulsification and Microencapsulation Properties of Gum Arabic. J. Agric. Food Chem., 46: 4551-4555.

Mirhosseini, H.; C. Tan; N. Hamid; S. Yusof (2008a). Optimization of the contents of Arabic gum, xanthan gum and orange oil affecting turbidity, average particle size, polydispersity index and density in orange beverage emulsion. Food Hydrocolloids. 22(7): 1212-1223.

Mirhosseini, H.; C. Tan; N. Hamid; S. Yusof (2008b). Effect of Arabic gum, xanthan gum and orange oil on flavor release from diluted orange beverage emulsion. Food Chemistry, 107(3): 1161-1172.

Randall R.; G. Phillips and P. Williams (1988). The role of the proteinaceous component on the emulsifying properties of gum Arabic. Food Hydrocolloids. 2(2): 131-140.

Seisun, D. (2002). Market overview. In: Gums and Stabilizers for the Food Industry, Vol. 11 pp. 3-9. Edited by P. A. Williams, \& G. O. Phillips. Cambridge Royal Society of Chemistry, London.

Taherian, A.; P. Fustier and H, Ramaswamy (2006). Effect of added oil and modified starch on rheological properties, droplet size distribution, opacity and stability of beverage cloud emulsions. J. Food Engineering. 77(3): 687-696.

Taherian, A.; P. Fustier; M. Britten and H. Ramaswamy (2008). Rheology and stability of beverage emulsions in the presence and absence of weighting agents: A Review. Food Biophysics. 3(3): 279-286.

Tesch, S.; Ch. Gerhards and H. Schubert (2002). Stabilization of emulsions by OSA starches. J. Food Engineering 54(2): 167-174.

Thevenet, F. (1988). Acacia gums: stabilizers for flavor encapsulation. In: Flavor Encapsulation, pp. 37-44. Edited by Risch, S. and G. Reineccius. Developed from a symposium sponsored by the division of Agriculture and Food Chemistry at the $194^{\text {th }}$ Meeting of ACS, New Orleans, Louisiana. Aug. 30-Sept. 4 (1987). ACS Washington DC 1988.

Thevenet, S. (1995). Acacia gums: Natural encapsulating agent for food ingredients. In: Encapsulation and Controlled Release of Food Ingredients, pp. 51-59. Edited by Risch, S. and G. Reineccius, Developed from a Symposium Sponsored by the Division of Agriculture and Food Chemistry at the $206^{\text {th }}$ National Meeting of ACS, Chicago, Illinois, Aug.22-27(1993). ACS Washington DC.

Williams, P. and G. Phillips (2000). Gum Arabic. In: Hand Book of Hydrocolloids, Chapter 9, pp. 155-168. Edited by Phillips, G. and P. Williams. CRS Press, New York.

Yadav, M.; D. Johnston; A. Hotchkiss and K. Hicks (2007). Corn fiber gum: A potential gum Arabic replacer for beverage flavor emulsification. Food Hydrocolloids. 21(7): 1022-1030.

Yadav, M.; D. Johnston and K. Hicks (2009). Corn fiber gum: New structure/function relationships for this potential beverage flavor stabilizer. Food Hydrocolloids. 23(7): 1488-1493. 